\title{
Innovation and Leapfrogging in the Chinese Automobile Industry: Examples from Geely, BYD and Shifeng
}

Hua Wang and Chris Kimble

\begin{abstract}
History provides numerous examples of incumbent market leaders being leapfrogged by newcomers that have exploited the opportunities offered by new technologies. In light of the growing number of ecological threats linked to the use of the internal combustion engine, can Chinese auto manufacturers, which are newcomers to the industry, beat out the established Japanese, European, and North American automakers in the race to produce a less environmentally damaging form of transport? Three case studies from the Chinese automobile industry reveal the different ways in which this leapfrogging might take place and highlight the impact that such developments might have on automobile manufacturers in Japan and the West, both for conventional and electric vehicles.
\end{abstract}

\section{Introduction}

In the eighteenth century, the Dutch ignored the new technology of cotton spinning, which was then taken up by the British, who grew rich from it. Similarly, in the nineteenth century, Germany adopted the new Bessemer process for steel making and dislodged Britain from its dominant position. In each of these cases, a newcomer embraced a technological innovation that had been ignored by the incumbents, and thereby displaced the existing market leader. More recently, in 2009, China displaced Japan to become the second richest country in terms of \$ GDP after the United States as, in 1966, Japan had displaced France.

Underlying the idea that it is possible for a newcomer to leapfrog over an incumbent is the notion that a particular technology has a particular trajectory that defines its development, and that the ability to recognize that path gives the newcomer the opportunity of catching up with or leapfrogging over an incumbent. Currently, some of the biggest challenges are environmental. As Goldemberg (1998) notes, the need to find cleaner, more energy efficient, and less environmentally damaging technologies has never been more urgent. High on the list are the need to reduce dependency on limited reserves of fossil fuels and to reduce pollution. Will the same logic apply? Will those who are able to predict the trajectory of green technologies inherit the future?

The automobile industry has been a particular focus of attention, with most major American, European, and Japanese car manufacturers actively developing a range of electric or hybrid electric vehicles. China, which is reported to emit more $\mathrm{CO}_{2}$ than the United States and Canada combined (Rogers \& Evans, 2011), and has some of the most polluted cities in the world (Walsh, 2012), has made the development of "New Energy Vehicles"- a classification that includes pure electric, electric hybrid, and other alternative energy vehicles-a national priority.

\section{Leapfrogging and Catching Up}

There is a strand in the writing on technological and economic development at the national level, as well as at the level of the firm, that argues that the development and use of a technology tends to follow a predefined pattern (Dosi, 1982). If this trajectory can be identified, then it should be possible to identify a gap in that trajectory and benefit from this knowledge by either closing the gap or by leaping ahead of one's competitors. Although the terms "catching up" and "leapfrogging" are used in both popular and academic articles, the 
precise meaning of these terms is not always clear. A detailed exploration of these ideas and a typology to more clearly differentiate between them follows.

\subsection{Catching Up}

Catching up is usually used to describe a situation where the gap between a newcomer and an incumbent is closed at an enhanced rate. Lee and Lim describe it thus: "... latecomer firms follow the same path as that taken by the forerunners. However, the latecomer firms go along the path in a shorter period of time than the forerunners" (2001, p. 426).

The term catching up is most often used in relation to industries in the developing nations catching up with those in the more developed nations. As previously noted, China is now the second richest country in terms of \$ GDP. It also has more Internet users than the United States and a space program that has already put a man into orbit. Consequently, the term catching up is of limited value when assessing the position of China as a whole but is still of value when considering certain areas of technology in which China might be still considered to be lagging.

\subsection{Leapfrogging}

Steinmueller defines leapfrogging as "... bypassing stages in capability building or investment through which countries were previously required to pass during the process of economic development" (2001, p. 194). In our previous work (Wang \& Kimble, 2011), we identified three distinct forms of leapfrogging, where the difference between each involves the type of innovation and level of knowledge required to make the leapfrog.

\subsubsection{Stage Skipping Leapfrogs}

The first type of leapfrog is probably the most obvious: jumping over a stage in the normal developmental path and moving straight to a more advanced stage. Lee and Lim (2001) give this example: When the Korean car manufacturer Hyundai began to manufacture its own engines, it skipped the stage of producing carburetor engines and moved straight to fuel injected engines. In general, a stage skipping leapfrog does not require much in the way of innovation. The main requirement is that the knowledge is freely available and the requisite social and technological infrastructures are in place.

\subsubsection{Path Creating Leapfrogs}

This type of leapfrog involves not so much jumping over a stage, but finding an alternative route from one stage to the next. By taking a path that others did not see or thought was impractical, the newcomer is able to sidestep the competition and take the lead. Doing this requires innovation and a higher level of technological capability. Lee and Lim (2001) cite the development of the CDMA technology used in mobile phones as an example. By developing an alternative route to creating a cell phone network, Korean firms were able to gain entry into new markets that would otherwise have been closed to them.

\subsubsection{Paradigm Changing Leapfrogs}

The final type of leapfrog involves a newcomer jumping so far ahead of the competition that it establishes a new technological paradigm. The idea is similar to that of disruptive innovation found in the strategic management literature. A disruptive technology disrupts a market by introducing a new, and often unlooked-for, value proposition. At first, the potential of such technologies appears limited; however, as the technology develops, it begins to meet the needs of mainstream consumers. At this point, the incumbent firms find they are unable to compete against the new value proposition and lose their position as market 
leaders. Bower and Christensen (1995) illustrate this with the way in which one type of disk drive displaced another as the market for personal computers began to develop.

\subsection{Leapfrogging and Innovation}

As Exhibit 1 outlines, the difference among these forms of technological development rests on the type of innovation and the level of knowledge needed in each. Catching up only needs an appropriate technological and social infrastructure and the ability to learn. Stage skipping requires knowledge of how to use and apply an existing technology. Path creating and paradigm changing leapfrogs require the creation of something new and unique. This might be finding an alternative path for the development of an existing technology or seizing the initiative and becoming a technological leader rather than a follower. In either case, the newcomer must cross a conceptual gap, with all that that implies, to successfully effect such a change.

Exhibit 1. A Typology of Paths for Technological Development

\begin{tabular}{|l|l|}
\hline $\begin{array}{l}\text { Path of Technological } \\
\text { Development }\end{array}$ & Type of Knowledge and Level of Innovation Required \\
\hline Catching Up & $\begin{array}{l}\text { Minimal, all that is required is to have the appropriate technological } \\
\text { and social infrastructure and to learn how to use the } \\
\text { technology/technique in its new setting. }\end{array}$ \\
\hline $\begin{array}{l}\text { Stage Skipping } \\
\text { Leapfrog }\end{array}$ & $\begin{array}{l}\text { Minimal if the stages in the existing process are clearly defined } \\
\text { and well understood; somewhat greater if the technology is } \\
\text { relatively new and untried. }\end{array}$ \\
\hline Path Creating Leapfrog & $\begin{array}{l}\text { The leapfrogger must understand both the technology and the } \\
\text { process that produces it, and have the technological and social } \\
\text { infrastructure to create and sustain an alternative route. }\end{array}$ \\
\hline $\begin{array}{l}\text { Paradigm Changing } \\
\text { Leapfrog }\end{array}$ & $\begin{array}{l}\text { The leapfrogger must understand the technology and the process } \\
\text { that produces it, but must also be able to make a conceptual leap } \\
\text { to visualize applying it in a new and radically different way. }\end{array}$ \\
\hline
\end{tabular}

\section{The Case Studies and Methodology}

Each case described in the sections that follow is the result of several years of work and has been published in peer reviewed academic journals. The primary data comes mainly from interviews with people directly connected to the case study company, with secondary data being collected from a variety of documentary sources. In some instances, the data from the original case studies have been updated for this article.

The first case study concerns Geely, a company that produces conventional automobiles powered by internal combustion engines (ICEs). A more detailed version of this case study, which focuses on product innovation, can be found in Wang and Kimble (2010b). The version of the case study that appears in this article has been updated and is supplemented by some additional data collection.

The second case study concerns BYD, a company that began life as a manufacturer of batteries, and has more recently moved into the production of electric vehicles (EVs). An earlier version of this case study, which focused on produce and process innovation and was based mainly on secondary data, has been published elsewhere (Wang \& Kimble, 2010a). The data for this version has been supplemented by information gained during a site visit and from interviews with managers and suppliers.

H. Wang and C. Kimble. Innovation and Leapfrogging in the Chinese Automobile Industry: Examples From Geely, BYD, and Shifeng. Global Business and Organizational Excellence, 32(6), 2013, pp. 617. DOI: $10.1002 /$ joe. 21510 
The final case concerns the Shifeng Group, a state owned enterprise established in 1993 to manufacture low speed, three wheeled, diesel-powered light trucks. More recently, Shifeng has become one of the key players in the development of the market for low speed electric vehicles (LSEVs) in China. An earlier version of this case study, which focused on business model innovation, can be found in Wang and Kimble (2012).

\section{Product Innovation at Geely}

The Geely Group was founded in 1984. It began as a manufacturer of refrigerators and refrigerator components, moved into the motorcycle industry in the early 1990s, and began manufacturing conventional automobiles in the late 1990s. Geely was China's first officially registered private automobile manufacturer and recently acquired Volvo to become China's ninth largest automobile manufacturer.

\subsection{Changes to Product Architecture at Geely}

Drucker (1985) uses the term "creative imitation" to describe what happens when a company takes an existing design and improves it to offer a better product or service. Chinese car manufacturers have gone beyond making ad-hoc improvements to existing designs, however, and have begun to develop a systematic approach to manufacturing based on what is termed quasi-open modular product architecture.

Product architecture is a conceptual representation of the physical components that make up a product. According to Fujimoto (2007), product architecture can be represented in terms of two dimensions: the degree of integration and the degree of openness. A high degree of integration means that a product needs to be produced as a single integrated unit, as all of the individual components are strongly interlinked. A low level of integration means that the components are relatively independent and can be treated as discrete modules. An open architecture implies the existence of industry level standards for components, which allows those components to be sourced across the entire industry. A closed architecture means that standards exist only within the boundaries of a single firm or group.

Although there is no single pattern to architectural evolution, Baldwin and Clark (1997) contend that the general trend is away from closed integral architectures and toward open modular architectures. In the automobile industry, Langlois (2002) maintains that the closed integral mass production model was dominant until the 1990s, when competitive pressures began to drive European carmakers toward a more modular mode of production. Examples of this can be found in platform sharing between Citroën and Peugeot in the PSA Group, and among Volkswagen, Audi, Skoda, and Seat in the Volkswagen Group; however, this does not approach the levels of openness and modularity found in the computer and telecommunications industry, where whole ranges of products can be produced using a few standardized, modular components.

In China, major elements from foreign cars, such as engines and chassis, have been copied and, over time and through repetitive remodeling, become quasi-modular components that can be mixed and matched to produce new cars in a way that is analogous to the construction of laptops and cell phones. Compared to the time and cost of developing a new car in the West, this approach is less expensive, results in a shorter time to market, and reduces the risks and uncertainties associated with product development.

At Geely, the move toward a more open, modular product architecture took place in two stages. Initially, it was thought that an automobile could be produced from scratch simply by combining capital, technology, and human resources. The first prototypes were poorly designed and effectively unusable. Following this initial failure, the company reworked its

H. Wang and C. Kimble. Innovation and Leapfrogging in the Chinese Automobile Industry: Examples From Geely, BYD, and Shifeng. Global Business and Organizational Excellence, 32(6), 2013, pp. 617. DOI: $10.1002 /$ joe. 21510 
strategy to focus on the imitation of existing vehicles. Components were reverse engineered and copied; however, unlike in many other companies, the architecture of the copied product was deliberately and consciously altered, so that the mixing and matching of high-level components from different sources became easier to achieve.

The recent models produced by Geely have reached a high level of modularity. For example, an engine produced by Geely will fit into bodies from several different manufacturers, while the automobiles produced by Geely can accommodate a range of engines that can be sourced from the open market. In short, the interface between the engine and the rest of the automobile has been designed to allow the manufacturer to mix and match these components in the same way as one might use standard components to build a range of PCs. This approach means that Geely is able to produce cars that are broadly comparable with their Western counterparts but at a fraction of the cost.

\section{Process Innovation at BYD}

BYD was founded in 1995. It became the world's second largest manufacturer of nickel cadmium ( $\mathrm{NiCd}$ ) batteries in 2002, and began building conventional ICE powered automobiles in 2003. It has now begun to produce a range of electric vehicles. In common with other Chinese automobile companies, BYD relies heavily on reverse engineering; however, it has also shown an ability to innovate in other areas.

\subsection{High Levels of Vertical Integration}

BYD has a high level of vertical integration in all aspects of its operations. Its automobile business has now expanded to a size where it would normally need to rely heavily on subcontractors; yet BYD's own business units still produce at least 70 per cent (in terms of volume) of the components needed by its vehicles.

Changes to the product architecture of their cars have meant that a number of special components need to be produced. The volume of production of these components is small, which means they would be costly if their production were outsourced. Lin Hongye, director of the Integrated Business Office at the Central Research Institute, explained: "The costs of in-house small volume production are equivalent to the price of external purchasing. However, the significant advantage is the speed of reaction. If we buy from the outside, coordination costs will be higher, and we may miss some market opportunity" (Gong, 2007). The management of BYD believes that this approach, combined with the move toward open modular product architectures, contributes to cost savings, helps quality control, and reduces the time to market.

This high level of vertical integration is also found in BYD's battery business, where it has exploited China's vast reserves of rare earth metals to become one of the leading producers of $\mathrm{NiCd}$ and lithium ion batteries and is now focusing on the development of a lithium-ironphosphate (LiFePO4) battery for use in heavy-duty EVs.

\subsection{Moving Away From Automation}

BYD was created when its founder, Wang Chuanfu, read a report that Japanese companies were moving away from NiCd batteries to high value-added nickel metal hydride (NiMH) and lithium ion batteries. He realized that the manufacturing base of NiCd batteries could move out from Japan to another country, such as China, and founded the Shenzhen BYD Battery Company Limited to take advantage of the opportunity. When it began to manufacture batteries, it replaced the capital-intensive Japanese style of production with a labor-intensive style more suited to Chinese industry. When it entered the automobile industry, it took a

H. Wang and C. Kimble. Innovation and Leapfrogging in the Chinese Automobile Industry: Examples From Geely, BYD, and Shifeng. Global Business and Organizational Excellence, 32(6), 2013, pp. 617. DOI: $10.1002 /$ joe. 21510 
similar approach to the manufacturing of cars. Rather than using automated production lines, it replaced specialized machines with standard machines, automated machines with semiautomated machines, and, wherever possible, imported machines with machines that were built in-house.

One of the potential risks of this approach is that BYD would not be able to maintain a consistent level of quality. To help resolve this problem, the company developed special tools and provided its workers with a program of education and training. Although the move away from an automated, capital-intensive production process could be seen as a backward step, BYD managers see this as part of an on-going learning process that takes into account local conditions and the low labor costs in China. When taken together with other changes, such as the way in which BYD manages its human resources, this approach has enabled BYD to become more flexible than other manufacturers and to reduce its costs.

\subsection{Human Resource Management}

Innovation in human resource management is seen as crucial if Chinese firms are to create and sustain technological innovations. Nonmaterial incentives are seen as being particularly important, both for the development of internal talent and for creating conditions where innovation can flourish. According to Wang Chuanfu, "BYD not only builds products, it is also good at building people, converting university graduates into engineering teams. BYD recruits several thousands of graduates, because we know the manufacturing of cars starts with manufacturing of talent, then equipment, then cars" (Tian, 2009).

BYD has created a compulsory training scheme for its employees, and actively seeks to retain the most talented. It has also invested heavily in its own social welfare system, including some of the activities that would normally be the responsibility of the state. It has built its own schools, from kindergarten through to middle schools and vocational colleges, and employees are provided with dormitories and apartments at prices significantly below the market rate. All these facilities have been constructed close to the workplace so that employees are able to access them easily on foot or by bicycle.

\section{Business Model Innovation at Shifeng}

The Shifeng (Group) Co., Ltd. is a state-owned enterprise established in 1993. It is located in Shandong province, where agriculture and wine production are the two largest industries. It is China's largest producer of agricultural machinery, three wheeled trucks, low speed light duty trucks, tractors, and single cylinder diesel engines. In 2007, the company began the production of low speed electric vehicles, which were designed as general-purpose farm vehicles that could be used to carry people and loads for short distances.

\subsection{Low Speed Electric Vehicles in China}

The typical LSEV consists of an accelerator, brakes, steering wheel, and a lead acid battery pack. The electric motor is connected directly to the accelerator; most models do not have a battery management or motor control system. There are now two main variants. The original version was based on the architecture of a golf cart, and another version was based around the architecture of a small automobile, such as the $Q Q$ from Chery. The typical top speed for such vehicles is between 40 and 60 kilometers per hour.

The structure of the Chinese economy has been an important factor in the development of the market for LSEVs. The per-capita annual income of rural households is less than a third of that for urban households. At 25,000 yen (\$3,900), the purchase price of an LSEV is less than a year's income - much more affordable than a small ICE powered car, priced at around

H. Wang and C. Kimble. Innovation and Leapfrogging in the Chinese Automobile Industry: Examples From Geely, BYD, and Shifeng. Global Business and Organizational Excellence, 32(6), 2013, pp. 617. DOI: $10.1002 /$ joe. 21510 
40,000 yen $(\$ 6,200)$. Another attractive feature for rural customers is its low running costs. The cost of the electricity needed to travel 100 kilometers is about 6 yen (\$0.90); for a small ICE powered automobile, the cost of gasoline for the same distance would be 49 yen (\$7.50). Finally, the lead acid battery can be charged overnight from an ordinary 220-volt outlet, which overcomes the problem of refueling gasoline-powered vehicles in rural China, where the gas station network is underdeveloped.

\subsection{The Market for LSEVs}

The Shifeng Group has invested heavily in research and development and has become a prime mover in attempts to develop the LSEV. Although production did not start until 2007, by the end of the year, 5,000 LSEVs had been sold, mostly to existing customers who lived in the immediate vicinity of the plant that produced them.

The potential market for LSEVs in China, however, is huge. Electric bicycles, scooters, and motorcycles are widely used. In 2009, there were 140 million users of such vehicles and 500 million users of standard bicycles. If 5 per cent of these switched to LSEVs, from this source alone, the market would be approximately 32 million people. Shifeng, however, faces a number of significant problems in developing this potential.

The main problem is that, according to the national laws, LSEVs cannot be used on public roads. Shifeng, however, operates under the jurisdiction of the regional government of Shandong province, where there are a number of other companies that produce LSEVs. In July 2008, the authorities there made a special arrangement to allow LSEVs to be used on public roads in Liaocheng, a city of more than one million inhabitants. In June 2009, Shifeng made further progress when it was given a license to produce electric sightseeing vehicles. This meant that LSEVs could now be sold in China, but only for use in designated areas.

Outside China, LSEVs have begun to find a market in the West, with institutional buyers, such as governments, hospitals, post offices, and airports, buying Chinese LSEVs as a lowcost green solution to providing a short distance runabout. Within China, however, a suitable business model is needed before their full potential can be realized.

\subsection{Finding a Suitable Business Model for LSEVs}

Although changes are being made, there remains a great deal of uncertainty about the future of LSEVs. While EVs, which are essentially a substitute for the ICE powered passenger car, are seen as national priorities, the LSEV remains on the margins. There are no accepted standards for LSEVs within China, but outside, Europe and North America have begun to make progress. In the United States, LSEVs are defined under Federal Motor Vehicle Security Standard No. 500 and Federal Crash Test Protocol TP50002 and are allowed on public roads in 46 states. In the European Union, the LSEV is classed as an electric quadricycle, defined by Framework Directive 2002/24/EC as a four wheeled vehicle that requires no crash testing and, in some countries, no driver's license to operate.

The Shifeng Group has mobilized all its resources with the aim of moving LSEVs from their current marginal status to being part of the mainstream Chinese automobile industry. Scientists and academics, as well as local and provincial decision makers, have been invited to visit the group, so that the implications for consumers, industry, and environmental protection can be explained. In parallel, the government of Shandong province established the "New Energy Vehicle Technology Innovation Alliance," which published a set of standards for terminology, technology, testing, safety, and environmental impacts for LSEVs in 2011. Despite this, however, the LSEV still does not feature in the official definition of a new energy vehicle.

H. Wang and C. Kimble. Innovation and Leapfrogging in the Chinese Automobile Industry: Examples From Geely, BYD, and Shifeng. Global Business and Organizational Excellence, 32(6), 2013, pp. 617. DOI: $10.1002 /$ joe. 21510 
Exhibit 2. The Notion of Leapfrogging Applied to the Case Studies

\begin{tabular}{|l|l|}
\hline Type & Potential for Leapfrogging in the Chinese Automobile Industry \\
\hline $\begin{array}{l}\text { Stage } \\
\text { Skipping } \\
\text { Leapfrog }\end{array}$ & $\begin{array}{l}\text { Using its dominance of the raw materials needed for the construction of } \\
\text { batteries, China could move ahead in refining the technology needed to } \\
\text { develop viable forms of electric vehicles (EVs) to replace the internal } \\
\text { combustion engine (ICE)-powered passenger car. }\end{array}$ \\
\hline $\begin{array}{l}\text { Path } \\
\text { Lreating } \\
\text { Leapfrog }\end{array}$ & $\begin{array}{l}\text { Changes in the product architecture needed to produce EVs could become a } \\
\text { route to exploit the trend toward more modular product architectures that } \\
\text { already exist in China and lead to a model for vehicle production that } \\
\text { Western manufacturers could not compete with. }\end{array}$ \\
\hline $\begin{array}{l}\text { Paradigm } \\
\text { Changing } \\
\text { Leapfrog }\end{array}$ & $\begin{array}{l}\text { If a widely applicable business model for low speed electric vehicles } \\
\text { (LSEVs) can be established, as China is already actively developing this } \\
\text { technology, it will take the lead. This, however, would require a significant } \\
\text { change in the current perception of the passenger car and an equally } \\
\text { significant change in public policy. }\end{array}$ \\
\hline
\end{tabular}

The technology for LSEVs exists and, as a product, LSEVs have a clear value proposition to low-income consumers in rural areas of China. Legislative changes within China could expand the local market further, but the key issue for the future development of the LSEV is the creation of a business model that will appeal to the Chinese urban and wider international market. Unlike the previous case studies, where changes have already taken place, the business model for LSEVs remains a work in progress.

\section{The Potential for Leapfrogging in the Chinese Automobile Industry}

Each of the case studies illustrates different examples of innovation that can be found in the Chinese automobile industry. In this section, we use the framework presented in Exhibit 1 to identify the potential for leapfrogging in the Chinese automobile industry, focusing in particular on the potential to develop green electrically powered alternatives to traditional ICE powered vehicles. Our findings are summarized in Exhibit 2.

\subsection{Stage Skipping Leapfrogs}

A stage skipping leapfrog gives a newcomer the opportunity to move straight to the next stage in the development of a technology. One area where such a leapfrog might take place is in the area of battery technology.

China has an effective monopoly of both the reserves and the production of rare earth minerals used for the batteries in EVs. It is perhaps not surprising that it is also at the center for innovations in battery technology. For example, BYD has developed a LiFePO4 battery that it claims will give its EVs a range of 300 kilometers and a maximum speed of 140 kilometers per hour. The power to weight ratio of batteries is a critical issue for the viability of EVs. If China were able to develop a new and more efficient form of battery, it would leap ahead of its competitors.

Similarly, as we have also noted elsewhere (Wang \& Kimble, 2011), China might be able to use the size of its domestic market combined with domestic legislation, such as its creation of a draft standard for charging plugs, to set de-facto international standards for EVs. If it could do this, China would leap ahead before its competitors could create their own.

$\mathrm{H}$. Wang and C. Kimble. Innovation and Leapfrogging in the Chinese Automobile Industry: Examples From Geely, BYD, and Shifeng. Global Business and Organizational Excellence, 32(6), 2013, pp. 617. DOI: $10.1002 /$ joe. 21510 


\subsection{Path Creating Leapfrogs}

Path creating leapfrogs find an alternative route to move from one-step to another in the development of a technology. If the use of quasi-open-modular architectures found in China proves to be a viable approach to automobile production, then it could mean that China's expertise in this type of production could form the basis for a path creating leapfrog.

Moving from an ICE powered vehicle to an EV involves a number of complex and interrelated changes. For example, the weight of the batteries not only affects the acceleration and cruising distance, but it also creates a new set of demands for the body shell that will carry them. Electric vehicles do not require the same sort of drive train as those powered by ICEs (for example, separate motors can power each wheel in an electric vehicle). Removing the engine block and drive train frees space, but also creates other problems for the architecture of the vehicle (for example, the behavior of the vehicle in a crash). Compared to the closed integral approach to production favored by most Western manufacturers, the more open modular approach to product architecture used by the Chinese could help simplify manufacturing and make the production of an EV more costeffective.

Similarly, although we would not argue that this is a foundation for a long-term competitive advantage, BYD's innovations in process technology also provide examples of Chinese firms finding alternatives to the established way of doing things. Although, from a Western perspective, BYD's initiatives might look like a step backward, from the Chinese perspective they are alternatives that make the most effective use of its existing resources and have allowed BYD to become both more flexible and more cost-effective.

\subsection{Paradigm Changing Leapfrogs}

A paradigm changing leapfrog involves a newcomer jumping so far ahead of the competition that it makes existing ideas obsolete and establishes a new technological paradigm. Perhaps the clearest example of this in the case studies concerns what might happen with the LSEV.

As we saw in the Shifeng case study, the LSEV is currently a marginal technology, but also one that has the possibility of being a disruptive technology (Bower \& Christensen, 1995) if the right business model can be found. The potential internal market for LSEVs is very large and, for the majority of Chinese consumers, there is no embedded stereotype of what a car should look like or what it should offer. Consequently, a novel means of transport, such as an LSEV, could be more readily accepted. On its own, however, even widespread acceptance of LSEVs in China would not amount to a paradigm shift.

Acceptance of the LSEV elsewhere, particularly in countries that have "grown up" with the motorcar, would require major changes in both the attitudes of consumers and in civic infrastructure. In particular, current perceptions about the social utility of car ownership and the assumptions that underpin much current urban planning would have to be questioned. Even in the countries with a strong automobile oriented culture, the same pressures of pollution and the scarcity of fossil fuels make themselves felt, and it is not beyond the realm of possibility that a new generation of consumers might make the shift to an alternative approach to personal mobility. If this were the case, then China has the potential to exploit its lead with LSEVs and execute a paradigm changing leapfrog.

\section{Implications for Western and Japanese Carmakers}

Having clarified what we mean by catching up and leapfrogging, and having looked at some examples from the Chinese automobile industry, we conclude by looking at what this might

H. Wang and C. Kimble. Innovation and Leapfrogging in the Chinese Automobile Industry: Examples From Geely, BYD, and Shifeng. Global Business and Organizational Excellence, 32(6), 2013, pp. 617. DOI: $10.1002 /$ joe. 21510 
mean for the established automobile manufacturers in Japan and the West. In line with our focus on the ecological challenges we face in the future, we will do this from the viewpoint of both conventional and electric vehicles.

\subsection{Chinese Innovation and Conventional Vehicles}

First, let us consider the threat that the innovations in product architecture and business processes made by Chinese automobile manufacturers pose for the established automobile manufacturers. Although European carmakers in particular have already been pushed in some ways toward modularization, China's expertise in quasi-modular architecture could form the basis for a technological leapfrog, while modularity remains at the group level in Europe and elsewhere. The assumption that cars are closed integral products built by corporations that can own and control the specifications of virtually every component that goes into them has not yet faced a significant challenge. If cars built in China using a more open product architecture begin to be viewed as broadly equivalent to their Western counterparts, manufacturers who have invested heavily in keeping their product architecture closed are likely to find it difficult to respond effectively.

\subsection{Chinese Innovation and New Energy Vehicles}

Turning now to the alternative to conventional ICE powered vehicles, China has made the development of new energy vehicles a national priority. The threat posed by developments in this area is more long-term and concerns both the development of the vehicles themselves and the business models that are used to commercialize them.

\subsubsection{Electric and Hybrid Electric Vehicles}

In Europe and North America, a passenger car is thought of as a long-distance vehicle that has the capability of reaching relatively high speeds. The size of the fuel tank, the power of the engine, and a long history of use have led Europeans and Americans to expect their cars to carry them for significant distances at speeds in excess of 100 kilometers per hour. In these markets, the passenger car represents a one-size-fits-all approach to both urban and long-distance mobility. The passenger car in the West is seen as a vehicle that will be used often, and its design, safety features, and level of luxury all reinforce this notion. It is perhaps not surprising that the plans for a new generation of EVs are being designed using the same criteria.

The development of such vehicles is a significant challenge involving the technology needed to power the vehicles, the development of an infrastructure needed to support them, and the business models needed to make an EV commercially viable. China has already invested heavily in the technology for such vehicles and has begun to develop standards for some aspects of the supporting infrastructure for EVs, such as plugs and connectors. In terms of business models, China is also examining different variations on charging systems, such as the "plugin" versus the "battery remove" approach to charging an EV (Wang \& Kimble, 2011). These offer China the scope not only to catch up on the technical lead the West has in battery management technology, but also to execute various forms of stage skipping and path creating leapfrogs in areas where it has already established a foothold.

\subsubsection{Low Speed Electric Vehicles}

Although the potential for stage skipping and path creating leapfrogs is clear, the potential for paradigm changing leapfrogs is, almost by definition, less clear. The LSEV offers many of the same advantages to Western and Chinese urban consumers as it does to those in rural China: low cost and the elimination of the need for a network of charging stations required for what might be termed traditional EVs. There is a possibility that the nascent, low-cost 
LSEV business model will succeed in China. For this to happen in the West, however, would require a major change in consumer sentiment and an equally major change in resource allocation.

For example, although most urban commuting distances are less than 20 kilometers and LSEVs could answer the basic daily transportation needs of most urban consumers, intercity journeys would still necessitate a suitable public transport or the ready availability of traditional ICE powered vehicles. The former would require the (re)creation of a public transport network that has been in decline for decades, while the latter would, to some extent, undermine the rationale for introducing EVs in the first place. If this model of personal mobility were to become accepted in the West, it would seriously undermine the model of the car as a long-distance, high-performance, luxury vehicle that underpins most of the automobile industry in Europe and North America. If this were to happen, it would open the possibility for China and Chinese automobile manufacturers to execute the elusive paradigm changing leapfrog that would propel them into an unchallenged position of dominance - at least, that is, until the next paradigm change.

\section{References}

Baldwin, C. Y., \& Clark, K. B. (1997). Managing in an age of modularity. Harvard Business Review, 75(5), 84-93.

Bower, J. L., \& Christensen, C. M. (1995). Disruptive technologies: Catching the wave. Harvard Business Review, 73(1), 43-53.

Dosi, G. (1982). Technological paradigms and technological trajectories: A suggested interpretation of the determinants and directions of technical change. Research Policy, 11(3), 147-162.

Drucker, P. F. (1985). Innovation and entrepreneurship: Practice and principles. New York, NY: HarperCollins.

Fujimoto, T. (2007). Architecturebased comparative advantage-A design information view of manufacturing. Evolutionary and Institutional Economics Review, 4(1), 55-112.

Goldemberg, J. (1998). Leapfrog energy technologies. Energy Policy, 26, 729-741.

Gong, X. (2007). BYD: The kangaroo model of car manufacturing. World Business Report. Retrieved from http:// oxford.icxo.com/htmlnews/2007/01/05/986451 1.htm

Langlois, R. N. (2002). Modularity in technology and organization. Journal of Economic Behavior \& Organization, 49, 19-37.

Lee, K., \& Lim, C. S. (2001). Technological regimes, catchingup and leapfrogging: Findings from the Korean industries. Research Policy, 30, 459-483.

Rogers, S., \& Evans, L. (2011). World carbon dioxide emissions data by country. Retrieved from http://www.guardian.co.uk/news/datablog/2011/jan/31/worldcarbondioxideem issionscountrydataco2

Steinmueller, W. E. (2001). ICTs and the possibilities for leapfrogging by developing countries. International Labour Review, 140, 193-210.

Tian, Y. (2009). BYD (Topic BYD). China Business Update. Retrieved from http://tianyongqiu.blog.sohu.com/108150165.html

Walsh, B. (2012). The world's most polluted places. Time Magazine. Retrieved from http://www.time.com/time/ specials/packages/completelist/0,29569,1661031,00.html

$\mathrm{H}$. Wang and C. Kimble. Innovation and Leapfrogging in the Chinese Automobile Industry: Examples From Geely, BYD, and Shifeng. Global Business and Organizational Excellence, 32(6), 2013, pp. 617. DOI: $10.1002 /$ joe. 21510 
Wang, H., \& Kimble, C. (2010a). Betting on Chinese electric cars? Analysing BYD's capacity for innovation. International Journal of Automotive Technology and Management, 10, 77-92.

Wang, H., \& Kimble, C. (2010b). Low cost strategy through product architecture: Lessons from China. Journal of Business Strategy, 31(3), 12-20.

Wang, H., \& Kimble, C. (2011). Leapfrogging to electric vehicles: Patterns and scenarios for China's automobile industry. International Journal of Automotive Technology and Management, 11, 312-325.

Wang, H., \& Kimble, C. (2012). The low speed electric vehicle-China's unique sustainable automotive technology? In A. Subic, J. Wellnitz, M. Leary, \& L. Koopmans (Eds.), Sustainable automotive technologies 2012 (pp. 207-214). Berlin and Heidelberg, Germany: Springer. 